\title{
Analisis Perawatan Mesin Pompa Sentrifugal dengan Metoda Failure Mode and Effect Analysis (FMEA)
}

\author{
Trisna Mesra \\ Program Studi Teknik Industri, Sekolah Tinggi Teknologi Dumai \\ Email: trisnamesra74@gmail.com
}

\begin{abstract}
ABSTRAK
PT X adalah perusahaan yang bergerak dalam bidang jasa penyimpanan atau penimbunan minyak CPO dari perusahaan luar kota Dumai maupun perusahaan sekitar lingkungan PT X. Dalam proses menimbun minyak CPO, PT X menggunakan Mesin Pompa Sentrifugal untuk menyalurkan CPO. Akibat adanya keluar masuk CPO dengan menggunakan pompa Sentrifugal secara maksimal, berdampak pada kerusakan pada pompa tersebut. Diantara kerusakan yang sering terjadi adalah Bearing cover retak, bearing rusak, mechanical seal bocor serta terjadinya kerusakan packing. Hal ini menyebabkan pompa tidak bisa berfungsi secara optimal, sehingga akan menganggu proses pembongkaran cpo ke tangki timbun. Oleh karena itu melakukan kegiatan perawatan pada sebuh pompa sebelum terjadi kerusakan menjadi sangat penting pada sebuah industri karena dapat mengurangi biaya perbaikan pompa dan menjaga keberlanjutan transfer dari mobil ke tangki timbun. penelitian ini akan menggunakan metode Failure Mode and effect Analysis (FMEA) untuk mengidentifikasikan kerusakan mesin dan menentukan prioritas komponen pompa sentrifugal dalam perawatan serta jenis perawatannya berdasarkan nila RPN (Risk Priority Number). Berdasarkan hasil perhitungan dengan menggunakan excel maka nilai RPN terbesar adalah komponen bearing dengan nilai 448. Tindakan perawatan preventif yang dilakukan terhadap bearing adalah pemberian lubrikan secara berkala.
\end{abstract}

Kata kunci: FMEA, severity, occurence, detection, risk priority number

\begin{abstract}
$P T X$ is a company engaged in the storage of CPO oil from companies outside the city of Dumai and companies around the PT X environment. In the process of stockpiling $C P O$ oil, PT X uses a centrifugal pump machine to distribute CPO. As a result of the maximum exit and entry of CPO using a centrifugal pump, it has an impact on the damage to the pump. Among the damages that often occur are cracked bearing covers, damaged bearings, leaking mechanical seals and damage to packing. This causes the pump to not function optimally, which will disrupt the process of unloading the CPO to the storage tank. Therefore, carrying out maintenance activities on a pump before damage occurs is very important in an industry because it can reduce pump repair costs and maintain sustainable transfers from cars to storage tanks. So this research focuses on problems that often occur in centrifugal pumps and how to determine centrifugal pump maintenance strategies. Then this study will use the Failure Mode and Effect Analysis (FMEA) method to identify engine damage and determine the priority of centrifugal pump components in maintenance and the type of maintenance based on the RPN value (Risk Priority Number). Based on the results of calculations using excel, the largest RPN value is the bearing component with a value of 448. Preventive maintenance measures taken to bearings are the provision of lubricants periodically
\end{abstract}

Keywords: FMEA, severity, occurence, detection, risk priority number 


\section{Pendahuluan}

PT X adalah perusahaan yang bergerak dalam bidang jasa penyimpanan atau penimbun minyak CPO dari perusahaan luar kota Dumai maupun perusahaan sekitar lingkungan PT X yang ingin menyimpan atau menimbun stok minyak mereka sebelum digunakan untuk keperluan lebih lanjut. Dalam proses menimbun minyak CPO, PT X menggunakan Mesin Pompa Sentrifugal untuk menyalurkan CPO. Akibat adanya keluar masuk CPO dengan menggunakan pompa Sentrifugal secara maksimal, tentu ada dampak yang bisa menimbulkan kerusakan pada pompa tersebut. Diantara kerusakan yang sering terjadi adalah Bearing cover retak, bearing rusak, mechanical seal bocor serta terjadinya kerusakan packing. Hal ini menyebabkan pompa tidak bisa berfungsi secara optimal, sehingga akan menganggu proses pembongkaran cpo ke tangki timbun. Oleh karena itu melakukan kegiatan perawatan pada sebuh pompa sebelum terjadi kerusakan menjadi sangat penting pada sebuah industri karena dapat mengurangi biaya perbaikan pompa dan menjaga keberlanjutan transfer dari mobil ke tangki timbun. Jadi penelitian ini fokus pada permasalahan yang sering terjadi pada pompa sentrifugal dan cara menentukan strategi perawatan pompa sentrifugal.

Perancangan Sistem Pemeliharaan Pada Mesin Tenun Mengunakan Metode Reliability Centered Maintenance (RCM) dilakukan oleh Machfud dalam Bajuri (2020). Berikutnya Penentuan strategi perawatan pada Pompa Reciprocating 211/212 PM-34 A/B dengan menggunakan metoda RCM I diteliti oleh Trisna Mesra dkk (2018). Sementara Pengukuran pengukuran efektivitas mesin cetak web offset dengan menggunakan metoda TPM dilakukan oleh Trisna Mesra (2019). Penentuan penjadwalan perawatan pompa sentrifugal menggunakan metoda RCM II dilakukan oleh Bajury dkk (2020) yang betujuan untuk mengurangi kerusakan pompa sentrifugal.

Sutrisno dkk (2015) telah membagi perawatan menjadi empat kategori yaitu reactive maintenance, preventive maintenance, predictive maintenance dan proaktive maintenance.

a. Reactive maintenance merupakan tindakan perawatan yang dilakukan pada saat mesin mengalami kerusakan mesin.. Kegiatan perawatan dengan reactive maintenance akan menimbulkan biaya besar karena akan menyebabkan proses produksi terhenti . Hal ini disebabkan karena tidak adanya perencanaan.

b. Preventive maintenance merupakan tindakan perawatan secara berkala berdasarkan perencanaan perawatan. Kegiatan perawatan ini merupakan tidakan perawatan yang dilakukan berdasarkan waktu perawatanyang telah direncanakan tanpa menunggu terjadinya kerusakan mesin.

c. Predictive maintenance, merupakan analisis kondisi peralatan berdasarkan prilaku peralatan saat beroperasi, sehingga dari analisis tersebut dapat diprediksi kapan peralatan dapat beroperasi secara normal.

d. Proactive maintenance merupakan proses perawatan yang dilakukan oleh seseorang yang sangat paham dengan keadaan mesinnya (operator produksi) sehingga sebelum memulai proses produksi maka akan dilakukan tindakan perbaikan sebelum proses terjadi kerusakan pada mesin. 


\section{Metode Analisis Kegagalan}

Sebelum melakukan tindakan perawatan, maka terlebih dahulu harus dilakukan analisis kerusakan mesin agar tindakan perbaikan yang dilakukan sesuai dengan jenis kerusakan. Ada berbagai macam alat yang dapat digunakan untuk menganalisis dan mengetahui sumber sumber serta akar penyebab kerusakan yang terjadi. Fishbone diagram merupakan alat yang digunakan untuk mencari akar penyebab permasalahan yang menyebabkan tidak efisiennya proses bisnis yang ada di rumah sakit menurut Kanti bose (2012). Sementara penelitian ini menggunakan metode Failure Mode Effect Analysis (FMEA) untuk mengidentifikasi penyebab kerusakan dan membuat mitigasi resiko berdasarkan peringkat kerusakan.

\section{Failure Mode and Effect Analysis (FMEA)}

Failure Mode and Effect Analysis adalah metode yang digunakan untuk mengidentifikasi bentuk kegagalan yang mungkin menyebabkan setiap kegagalan fungsi dan untuk memastikan pengaruh kegagalan berhubungan dengan setiap bentuk kegagalan. Untuk mengidentifikasi penyebab kegagalan pada setiap failure atau kegagalan yang terjadi pada komponen

Tahapan Analisis FMEA :

a. Identifikasi fungsi produk.

b. Identifikasi kegagalan potential (potential failure mode).

c. Identifikasi akibat kegagalan (potential effects of failure).

d. Analisis tingkat keseriusan kegagalan (severity of effect).

e. Identifikasi sebab-sebab kegagalan (potential causes of failure).

f. Analisis frekuensi kegagalan (occurrence).

g. Metode deteksi kegagalan (detection method).

h. Analisis tingkat pendeteksian (detection).

i. Penghitungan Risk Priority Number (RPN).

j.

\section{Metode Penelitian}

Dalam penelitian ini data yang diambil adalah data dari Mesin Pompa Sentrifugal di PT X Dumai. Dari Mesin Pompa Sentrifugal tersebut memiliki komponen mesin yang sering mengalami kerusakan selama periode 22 bulan terakhir. Terhitung dari bulan Maret 2019 hingga bulan Desember 2020, data komponen tersebut ialah:

1. Packing

2. Mechanical Seal

3. Bearing

4. Bearing Cover

Oleh karena itu diperlukan perencanaan preventive maintenance yang baru untuk menghindari terjadinya kerusakan dan memaksimalkan proses transfer CPO dari mobil ke tangki timbun. Penelitian ini menggunakan metode kuantitatif dengan 
melakukan survey, observasi,interview dan proses analisis dokumen yang dimiliki perusahaan. Gambar berikut memperlihatkan metode pelaksanaan penelitian.

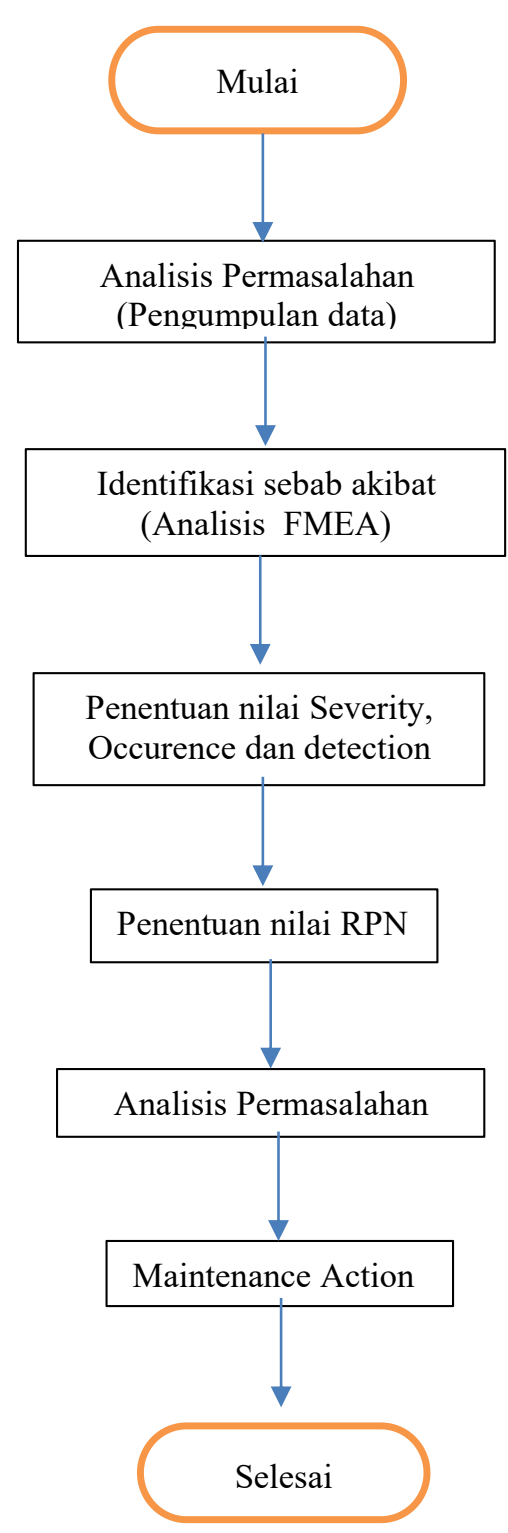

Gambar 1. Flowchart penelitian.

FMEA digunakan untuk mengidentifikasi komponen pompa yang sering mengalami kerusakan. Hasil dari proses analisis tersebut adalah tipe kerusakan yang potensial terjadi pada proses transfer CPO, dampak kerusakan dan prioritas komponen pompa yang akan dilakukan berdasarkan nilai RPN tertinggi. 


\section{Hasil dan Pembahasan}

Pengumpulan data yang dilakukan oleh peneliti yaitu dengan melakukan observasi langsung ke lapangan yaitu di PT X Dumai, wawancara kepada staff yang terkait serta mencari informasi yang berkaitan dengan penelitiaan.

Tabel 1. Spesifikasi Pompa Sentrifugal SIHI ZLND 100-250

\begin{tabular}{|c|c|c|}
\hline No & Item & Specification \\
\hline 1 & Merk & SIHI \\
\hline 2 & Type & ZLND 100-250 \\
\hline 3 & Kapasitas & 250 Ton \\
\hline 4 & Material & All SS 316 \\
\hline 5 & Driver & Motor Listrik \\
\hline 6 & Sealling & Mechanica Seal \\
\hline 7 & Power & $90 \mathrm{kw} / 380 \mathrm{~V} / 50 \mathrm{~Hz}$ \\
\hline 8 & RPM & $2950 \mathrm{RPM}$ \\
\hline 9 & Outlet & $4 "$ \\
\hline
\end{tabular}

Pompa sentrifugal terdiri dari beberapa komponen. Berikut akan diberikan nama nama komponen utama dan fungsi masing masing komponen pompa sentrifugal:

1. Casing, yang berfungsi untuk menurunkan kecepatan aliran (flow) fluida yang masuk ke dalam pompa. Menuju sisi outlet pompa, volute casing didesain membentuk corong yang berfungsi untuk mengkonversikan energi kinetik menjadi tekanan dengan jalan menurunkan kecepatan dan menaikkan tekanan, hali ini juga membantu menyeimbangkan tekanan hidrolik pada shaft pompa.

2. Impeler, adalah bagian yang berputar dari pompa sentrifugal, yang berfungsi untuk mentransfer energi dari putaran motor menuju fluida yang dipompa dengan jalan mengakselerasinya dari tengah impeller ke luar sisi impeller

3. Poros (Shaft) adalah bagian yang mentransmisikan putaran dari sumber gerak, seperti motor listrik, ke pompa. Yang perlu kita perhatikan adalah, pada sebuah pompa sentrifugal yang bekerja di titik efisiensi terbaiknya, maka gaya bending porosnya akan secara sempurna terdistribusikan ke seluruh bagian impeller pompa.

4. Bearing, berfungsi untuk menahan (constrain) posisi rotor relatif terhadap stator sesuai dengan jenis bearing yang digunakan. Bearing yang digunakan pada pompa yaitu berupa journal bearing yang berfungsi untuk menahan gaya berat dan gaya-gaya yang searah dengan gaya berat tersebut, serta thrust bearing yang berfungsi untuk menahan gaya aksial yang timbul pada poros pompa relatif terhadap stator pompa.

5. Kopling, berfungsi untuk menghubungkan dua shaft, dimana yang satu adalah poros penggerak dan yang lainnya adalah poros yang digerakkan. Kopling yang digunakan pada pompa, bergantung dari desain sistem dan pompa itu sendiri. 
Macam-macam kopling yang digunakan pada pompa dapat berupa kopling rigid, kopling fleksibel, grid coupling, gear coupling, elastrometic coupling, dan disc coupling.

6. Sistem Packing pada pompa adalah untuk mengontrol kebocoran fluida yang mungkin terjadi pada sisi perbatasan antara bagian pompa yang berputar (poros) dengan stator. Sistem sealing yang banyak digunakan pada pompa sentrifugal adalah mechanical seal dan gland packing.

7. Sistem Lubrikasi pada pompa berfungsi untuk mengurangi koefisien gesek antara dua permukaan yang bertemu sehingga mengurangi resiko keausan. Lubrikasi pada pompa terutama digunakan pada bearing. Sistemnya dapat berupa lub oil atau juga tipe greas tergantung dari desain pompa itu sendiri.

Berdasarkan hasil pengumpulan data frekuensi kerusakan komponen komponen pompa sentrifugal ditemukan empat komponen yang memiliki data kerusakan yang tinggi, yang dapat dilihat pada tabel 2 .

Tabel 2. Rekapitulasi kerusakan komponen pompa sentrifugal dari Bulan Maret 2019 sampai Desember 2020

\begin{tabular}{|l|c|}
\hline \multicolumn{1}{|c|}{ Nama Komponen } & Frekuensi Kerusakan (Kali) \\
\hline Packing & 10 \\
\hline Bearing cover retak & 10 \\
\hline Bearing rusak & 15 \\
\hline Mechanical Seal rusak & 14 \\
\hline
\end{tabular}

Tabel 2 memperlihatkan frekuensi kerusakan setiap komponen kritis pada pompa sentrifugal, dimana frekuensi kerusakan tertinggi yaitu Bearing dan mechanical seal.

Berdasarkan hasil penelitian yang dilakukan di PT X ditemukan bahwa beberapa komponen dari pompa sentrifugal mengalami kegagalan saat pompa sedang beroperasi, sehingga membutuhkan perencanaan perawatan pencegahan (preventive maintenance) untuk mencegah terjadinya kerusakan saat pompa dalam proses operasi. Sebelum melakukan tindakan korektif, analisis mengenai jenis kerusakan yang sering muncul serta pengaruhnya diperoleh dengan menggunakan metode FMEA yang ditujukan pada tabel berikut :

Tabel 3. Analisis failure mode effect analysis

\begin{tabular}{|l|l|l|l|l|l|l|l|l|}
\hline No & Part & $\begin{array}{l}\text { Potential } \\
\text { Failure Mode }\end{array}$ & $\begin{array}{l}\text { Potential } \\
\text { Effect of } \\
\text { Failure }\end{array}$ & $\begin{array}{l}\text { Potential } \\
\text { cause of } \\
\text { Failure }\end{array}$ & S & D & RPN \\
\hline 1. & Bearing & $\begin{array}{l}\text { Bearing } \\
\text { longgar atau } \\
\text { goyang }\end{array}$ & $\begin{array}{l}\text { Operasi } \\
\text { berhenti }\end{array}$ & $\begin{array}{l}\text { Kedudukan } \\
\text { bearing tidak } \\
\text { tepat/ } \\
\text { Bearing aus }\end{array}$ & 8 & 8 & 7 & 448 \\
\hline 2. & $\begin{array}{l}\text { Mechanical } \\
\text { seal }\end{array}$ & Bocor & $\begin{array}{l}\text { Operasi } \\
\text { berhenti }\end{array}$ & $\begin{array}{l}\text { Karena } \\
\text { tekanan } \\
\text { tinggi }\end{array}$ & 9 & 7 & 4 & 252 \\
\hline
\end{tabular}




\begin{tabular}{|l|l|l|l|l|l|l|l|l|}
\hline 3. & $\begin{array}{l}\text { Bearing } \\
\text { cover }\end{array}$ & Retak & $\begin{array}{l}\text { Operasi } \\
\text { berhenti }\end{array}$ & $\begin{array}{l}\text { Getaran } \\
\text { tinggi }\end{array}$ & 6 & 5 & 8 & 240 \\
\hline 4. & Packing & Rusak & $\begin{array}{l}\text { Operasi } \\
\text { ternganggu }\end{array}$ & $\begin{array}{l}\text { Karena } \\
\text { putaran dan } \\
\text { panas yang } \\
\text { tinggi }\end{array}$ & 7 & 4 & 5 & 140 \\
& & & & & \\
\hline
\end{tabular}

Analisis kegagalan (failure analysis) untuk menetapkan nilai Severity (S), Occurence(O), dan Detection (D) pada tabel 3 ditentukan berdasarkan rekap hasil penilaian yang diberikan responden atau tenaga ahli maintenance yang berada di PT X. Berikutnya dilakukan perhitungan Risk Priority Number (RPN) untuk setiap komponen/part kritis pompa sentrifugal dengan cara mengalikan nilai severity dengan occurence dan detection. Dimana hasil RPN komponen yang memiliki nilai paling tinggi mengidentifikasikan bahwa komponen tersebut mendapat prioritas untuk dievaluasi dan dianalisis sebagai acuan dalam membuat langkah perbaikan perawatan pompa. Nilai RPN tertinggi adalah untuk komponen bearing dan mechanical seal sebesar 448 dan 252. Tindakan preventive maintenance yang dilakukan terhadap bearing adalah selalu memberikan lubrikan secara berkala, pergantian terhadap mechanical seal sesuai jadwal.

\section{Simpulan}

Berdasarkan pengolahan data dan analisis maka nilai RPN yang digunakan sebagai dasar dalam pemberian usulan tindakan perbaikan part atau komponen pompa sentrifugal. Komponen kritis pompa sentrifugal yang berpengaruh terhadapa kelancaran proses transfer CPO meliputi; bearing, mechanical seal, bearing cover dan packing. Nilai RPN tertinggi adalah untuk komponen bearing sebesar 448. Tindakan perbaikan yang akan ditetapkan untuk PT X adalah sebagai berikut :

1. Bearing

Penyebab terjadinya bearing longgar dan goyang adalah kedudukan bearing yang tidak tepat dan bearing aus. Tindakan perbaikan yang diusulkan adalah memberikan lubrikan secara berkala.

2. Mechanical seal

Penyebab terjadinya mechanical seal bocor adalah karena tingginya tekanan. Tindakan perbaikan yang dilakukan adalah pergantian mechanical seal sesuai jadwal.

\section{Daftar Pustaka}

Kurniawan, F., (2013). Teknik dan Aplikasi Manajemen Perawatan Industri. Yokyakarta: Graha Ilmu.

Bayjury, Moh.dkk (2020), Penentuan Interval Waktu Perawatan pada Komponen (bearing, mechanical seal, bearing cover dan packing mesin pompa sentrifugal di PT X Dumai) 
Mesra, T, (2019) , Pengukuran efektifitas mesin cetak web offset menggunakan Overall Equipment Effectiveness, BULTEK, volume 14 nomor 3.hal 169-179.

Mesra, T dkk(2018), Maintenance Pompa Reciprocating 211/212 PM-4 A/B Menggunakan Metode RCM di PT Pertamina Dumai, volume 13 no 3 hal 175183

Sutrisno A, Gunawan I, Tangkuman S. Modified Failure Mode and Effect Analysis (FMEA) Model for Accessing the Risk of Maintenance Waste. Procedia Manuf [Internet].2015 [cited $2019 \quad$ Sep 19];4:23-9. Available from:https://linkinghub.elsevier.com/retrieve/pii/S2351978915011269 